\title{
Sero Prevalence of Rubella Immunity in Pregnant Women in Kerala, India
}

\author{
Thayyil Jayakrishnan ${ }^{1 *}$, Anitha Murkoth ${ }^{2}$, Biju George ${ }^{1}, B^{\prime}$ haskar Rao ${ }^{1}$, Kuniyil Vidya $^{5}$
}

\section{Thayyil Jayakrishnan ${ }^{1 *}$, Anitha Murkoth², Biju George', Bhaskar Rao', Kuniyil Vidya ${ }^{5}$}

'Department Community Medicine, Govt Medical College, Calicut. Kerala. INDIA.

${ }^{2}$ Department Microbiolgy. Govt Medical College, Calicut. Kerala. INDIA.

${ }^{5}$ Apartment 206, 10300 W Blue mount road, Wisconsin, USA.

\section{Correspondence}

DrThayyil Jayakrishnan MD,

Associate Professor, Department Community Medicine, Govt Medical College, Calicut. Kerala, INDIA.

Ph.no: 9447953005

Email: drjayakrishnant@yahoo.com

\section{History}

- Submission Date: 05-05-2016;

- Review completed: 21-07-2016;

- Accepted Date: 25-08-2016.

DOI : 10.5530/ijmedph.2016.4.9

Article Available online

http://www.ijmedph.org/v6/i4

\section{Copyright}

(C) 2016 Phcog.Net. This is an openaccess article distributed under the terms of the Creative Commons Attribution 4.0 International license.

\begin{abstract}
Introduction: The endemicity of rubella has been well established in India and immunity to rubella in pregnant women can indirectly hint at the risk of acquiring Congenital Rubella Syndrome CRS. In India Rubella vaccine has not been introduced in universal immunization program (UIP) at national level and has been used in only in private sectors which cover only a small proportion of population. In the state no community based studies were conducted among pregnant women to study the immunity against rubella which will reflect their vulnerability to future infection. Aims: The present study was carried out primarily to assess the IgG seroprevalence of rubella in pregnant women. Second, to identify potential predictors of rubella immunity like age, gravidity and previous abortions. Material methods: The study was conducted in Mavoor panchayath area of Kozhikode district, Kerala. The subjects were pregnant women $(n=70)$ of any period of gestation who were permanent residents of the area were selected by systematic random sampling from antenatal register. The data collection, blood sample collection and estimation of Rubella specific I G antibody was done by enzyme linked immunesorbent assay (ELIZA) method. Results: The mean age was $24.7 \pm$ (SD4.3) years. The mean titre value was $192.45 \pm 102.58 \mathrm{IU}$ and $94.3 \%$ (95\% Cl $86.2-97.8)$ were Ig G positive. There was no difference between IgG levels among different trimesters, age or gravidity. Among those with history of abortion $100 \%$ and those without history of abortion $96.4 \%$ were $\lg \mathrm{G}$ positive. Conclusion: This study indicates that rubella is still an endemic condition in India, majority of pregnant women have acquired immunity towards rubella. More detailed epidemiological studies by taking samples from different states may be needed for a basis of national immunization program.

Key words: Pregnant women, Rubella immunity, IgG antibody, Congenital Rubella Syndrome, Prevalence.
\end{abstract}

\section{INTRODUCTION}

Rubella infection occurring just before conception and during early pregnancy may result in miscarriage, fetal death, or congenital defects known as congenital rubella syndrome (CRS) in up to $90 \%$ of cases. ${ }^{1}$ The highest risk of CRS is found in countries with high rates of susceptibility to rubella among women of childbearing age which may vary considerably among and within countries according to the epidemiological and socioeconomic differences. ${ }^{1,2}$ Before the introduction of rubella vaccine, the estimated world incidence of CRS varied from 0.1- 4/1000 live births. ${ }^{1-3}$ A study conducted by World Health Organization (WHO), in developing countries $10-25 \%$ of the women tested were seronegative. ${ }^{4}$ Even the susceptibility rate of $10 \%$ among adult women can result in CRS out breaks. ${ }^{1}$ Out of the 194 WHO member states, 140 have introduced rubella vaccine; still 114 Countries have reported CRS. ${ }^{5}$ Rubella and CRS control was the goal established in the South-East Asia Region as an initial step towards elimination. ${ }^{5}$
Since up to $60 \%$ of rubella infections are sub clinical, susceptibility or immunity to rubella can be ascertained only by serological tests. ${ }^{2,6}$ Several sero- epidemiological surveys from other countries have reported that a substantial number of women reach childbearing age without acquiring natural immunity to rubella and are susceptible to rubella virus infection during pregnancy. ${ }^{6,7}$

The endemicity of rubella has been well established in India and immunity to rubella in pregnant women can indirectly hint at the risk of acquiring CRS. ${ }^{2,6}$ In India Rubella vaccine has not been included in universal immunization program at national level and has been used only in private sector covering a small proportion of population. So the probability of increasing susceptibility to rubella among women of child bearing age due to "paradoxical effect" cannot be ruled out. ${ }^{1,2}$ No country-wide estimates of CRS burden and susceptibility to rubella infection are available in India as there is lack of a national surveillance and registry. ${ }^{8}$ In India few studies conducted previously in northern states reported immunity against rubella among pregnant women vary from 
$53 \%$ to $94.1 \% .^{9}$ A hospital based study conducted from the state Kerala reported the prevalence rate as $65.7 \% .^{10}$ All these were conducted before the wide spread use of rubella vaccine among children. Between countries and within the country the rubella immunity in women present with wide spread geographical variations which may depend upon the factors such as, net birth rate, population density, opportunities for entry of virus, level of herd immunity at the time of virus introduction and ethnicity of the population. ${ }^{3,11}$ Before introduction of any programme to control rubella, features of rubella transmission and risk of infection in pregnancy in that particular community should be considered. ${ }^{12}$ Presently this is relevant in Indian situation where there exist a sub population immunization with rubella vaccine which may lead to age shifting and future risk of CRS as happened in countries like Greece and CostaRica. ${ }^{1,12,13}$ In these context to evaluate the disease burden of rubella and CRS before vaccine introduction the sero surveillance among pregnant women are very important. ${ }^{1,5}$

The present study was carried out primarily to assess the IgG seroprevalence of rubella in pregnant women to know their immune status. Second, to identify potential predictors of rubella immunity including age, gravidity, parity, and previous abortions.

\section{MATERIAL METHOD}

The descriptive study was conducted after getting approval from Institutional ethics committee and was done in Mavoor panchayth area of Kozhikode district, Kerala, India. The area was selected by two stage random method. At first the blocks in the district was listed and from the list Kundamangalam block was selected and from the selected block the panchayaths were listed and one area was selected. As per the census 2011 the area had a population of about 30000 with a crude birth rate of 14 per1000 population and total number of pregnant women registered in the primary health centre (PHC) during the year till the month of the study was 390. The subjects were pregnant women of any period of gestation or parity who were permanent residents of the area. From the antenatal register available from the PHC 100 women were selected by systematic random sampling and were invited to attend the screening camps conducted in four days (25X4) at PHC. The subjects were enrolled and data collection was done after getting written informed consent from them. With expected rubella specific Ig $\mathrm{G}$ prevalence among women as $80 \%{ }^{10}$ with a precision of \pm 8 the minimum sample size required was 100 . (Epi info 7 soft ware WHO).

The data collection and blood sample collection was done by conducting screening camps on fixed days. From the subjects the obstetric details like gravidity, parity, number of living children, congenital anomaly, and abortion were collected using a standardized questionnaire by direct interview by the investigators.

The morbidity details of present or past history of any exanthematous fever, past history of hospitalization were collected. Medical examination was conducted to detect any disease-fever/exanthema/lymph node enlargement, deafness/anomaly-cataract, congenital heart disease etc.

From each subject $5 \mathrm{ml}$ venous blood was collected from antecubital vein with aseptic precautions using vacutainer with gel separators, serum was separated and was transported to microbiology laboratory at Medical College in vaccine carriers at temperature below 4 degree centigrade on the same day, stored at -20 degree centigrade till estimation. The estimation of Rubella specific -Ig G antibody was done by quantitative enzyme linked immunosorbent assay (ELIZA) method using the kit BEIA Rubella IgG Quant technogenitics SRL, Italy with relative sensitivity, and specificity of $100 \%$ using standard procedures by laboratory technician with adequate experience under the supervision of microbiologist. The results were expressed as IU/ml. As per the product manual (BEIA Rubella IgG Quant. 2006) Samples that shows an Ig G titre value of $>15$ IU was taken positive and $8-15$ IU as equivocal and $<8$ IU as negative. About $10 \%$ of the samples were retested at Kasthurba medical college, Manipal laboratory a central laboratory accredited by the National Accreditation Board for Testing Laboratories (NABL) of the Department of Science and Technology, Government of India and validity and consistency was assured.

Statistical analysis was performed using the Statistical Package for the Social Science (SPSS), version 16 for Windows. Continuous variables were summarized using descriptive statistics in terms of means, standard deviations while qualitative variables were presented as frequency and percentages along with 95\% confidence intervals (95\% CI) calculated using Wilson score method using Open Epi software.

\section{RESULTS}

Out of the 100 women invited, 85 have reported for the screening camp and gave informed consent (85\%), of which we could collect blood samples from 80 women. From 5 women venupuncture was failed. On reaching the laboratory 10 samples were lysed and estimation of IgG was done in 70 samples.

The mean age were $24.7 \pm$ (SD4.3) years ranging from 18 to 33 . Of the total 70 women 38 were in first, 24 in second and 18 in third trimester of pregnancy. Nobody had received Rubella vaccine previously. The mean titre value was $192.45 \pm 102.58$ IU (Range 5 to $408 \mathrm{IU}$ ). The IgG was positive in $94.3 \%(66 / 70)$, negative in $3 \%(2 / 70)$ and equivocal in $3 \%$ $(2 / 70)$ of women. Immunity to rubella was queried as a function of several patient factors including age, gravidity, parity and history of abortion. Age group wise $\operatorname{IgG}+$ prevalence was given in Table 1 and there was no change in the antibody level showing that rubella is widely circulating in the community, majority have acquired rubella infection in early (Table 1).

The gravidity ranges from 1 to 5 and there was no significant change in IgG titre with order of pregnancy (Table 2). Twenty six (37.1\%) women were prime and of them $96 \%$ were IgG positive (Table 2 ). The parity ranges from zero to 4 , the titre value have no relation with parity (Table 3 ) Thirteen women (18.5\%) had history of abortion in past and all of them $(100 \%)$ were IgG positive. Among those without history of abortion 96.4\% were IgG positive and the difference was not significant $(\mathrm{P}=0.98)$. Two women had history of children with minor congenital anomaly (Syndactyly) which were clinically not due to congenital rubella, both were IgG positive.

\section{DISCUSSION}

The serological surveys play a precise role in defining rubella disease epidemiology and to contain the consequences of the disease. In our study conducted among pregnant woman $94.3 \%$ (95\% CI 86.2-97.8) of them have protective level of IgG. Since none of them have received immunization against rubella the immunity may be due to naturally acquired rubella infection during their life years prior to pregnancy giving evidence that rubella is still endemic in the area. The rest 5.7\% (95\% CI 2.2-13.8) were susceptible and could acquire infection during pregnancy period. There is considerable variation in the prevalence of rubella IgG among women of child bearing age in different geographical regions in India ,ranging from $65.7 \%$ in Trivandrum, Kerala, $68.8 \%$ in Punjab, $87.2 \%$ in Delhi and $88.2 \%$ in Utter Pradesh(UP). ${ }^{3,6,10,14}$ Most of the above studies were done before the wide spread use of rubella vaccine among children in India. From the neighboring country Bangladesh it was reported as $84.3 \% .^{9}$ The present study it was found to be high (>90\%) similar to European countries and United States which in corporate rubella vaccines in their national programmes. ${ }^{15}$ 
Table 1: Relation IgG positivity with Age of Women

\begin{tabular}{cccc}
\hline \multirow{2}{*}{ Age group } & \multicolumn{3}{c}{ IgG positive } \\
\cline { 2 - 4 } & Number & Percentage & $95 \% \mathrm{Cl}$ \\
\hline $\begin{array}{c}\text { Below 20 years } \\
(\mathrm{n}=15)\end{array}$ & 14 & 93.3 & $70.2-98.8$ \\
$\begin{array}{c}20 \text { to 30 years } \\
(\mathrm{n}=47)\end{array}$ & 45 & 95.7 & $85.8-98.8$ \\
$\begin{array}{c}\text { Above 30 years } \\
(\mathrm{n}=8)\end{array}$ & 07 & 87.5 & $52.9-97.8$ \\
$\begin{array}{c}\text { Total } \\
(\mathrm{n}=70)\end{array}$ & 66 & 94.3 & $86.2-97.8$ \\
\hline
\end{tabular}

Table 2: Relation IgG positivity with Gravida of Women

\begin{tabular}{cccc}
\hline \multirow{2}{*}{ Gravida } & \multicolumn{3}{c}{ IgG positive } \\
\cline { 2 - 4 } & Number & Percentage & $95 \% \mathrm{Cl}$ \\
\hline $\begin{array}{c}1 \\
(\mathrm{n}=26) \\
2\end{array}$ & 25 & 96.2 & $81.1-99.3$ \\
$(\mathrm{n}=23)$ & 23 & 100 & $85.7-100$ \\
3 & & & \\
$(\mathrm{n}=12)$ & 10 & 83.3 & $55.2-95.3$ \\
4 & & & \\
$(\mathrm{n}=7)$ & 06 & 85.7 & $48.7-97.4$ \\
5 & 02 & 100 & $34.3-100$ \\
$(\mathrm{n}=2)$ & & & $86.2-97.8$ \\
Total & 66 & 94.3 & \\
\hline
\end{tabular}

Table 3: Relation IgG positivity with Parity of Women

\begin{tabular}{cccc}
\hline \multirow{2}{*}{ Parity } & \multicolumn{3}{c}{ IgG positive } \\
\cline { 2 - 4 } & Number & Percentage & $95 \% \mathrm{Cl}$ \\
\hline 0 & 29 & 100 & $88.3-100$ \\
$(\mathrm{n}=29)$ & & & $80.5-99.3$ \\
1 & 24 & 96 & \\
$(\mathrm{n}=25)$ & & & $49.0-94.3$ \\
2 & 08 & 80 & $37.6-96.4$ \\
$(\mathrm{n}=10)$ & & & \\
3 & 04 & 80 & $20.7-100$ \\
$(\mathrm{n}=5)$ & & 100 & $86.2-97.8$ \\
4 & 01 & &
\end{tabular}

Though the women belonged to different periods of pregnancy there was no difference between IgG levels among different trimesters. Compare to other age groups the age 20-30 year group have high positivity (95.7 $\% .95 \%$ CI 85.8-98.8) but the difference was not statistically significant (Table 1). This prevalence rate gave the evidence that the majority women have acquired immunity following infection before the age of 20. The study from Uttar Pradesh (UP), Amrithasar and Bangladesh showed higher prevalence among 20-25 age (88.2\%), 26-35 yea r(77.2\%),25-30 year $(77.8 \%)$ respectively compared to other age groups without any statistical significance. ${ }^{3,9,14}$ The sero surveillance study conducted in the same area among 250 adolescent girls (13-15 Years) at the same period by the authors reported that $68.3 \%$ of them have acquired natural immunity against rubella (Un published data). ${ }^{16}$

Similar to our findings (Table 3 ) a previous hospital based study from the southern part of state also reported that the rubella immunity have no relation with parity. ${ }^{10}$ A study from UP reported that primi have higher rate of immunity compared to multigravida ( $89 \%$ and $84.3 \%$ ) which was also non significant. ${ }^{14}$

In our study 13 (18.5\%) women with ever history of abortion all (100\%) were IgG positive compared to women (57) with no history of abortion ( $96.7 \%)(\mathrm{P}=0.97)$. It was similarly reported from Delhi $(91.7 \%$ and 85.7\%), Punjab (73.2\% and 69.5\%), and Bangladesh $(86.8 \%$ and 80.65\%). ${ }^{3,6,9}$ A study from Andra Pradesh reported that the IgM antibody prevalence was higher (12.6\% and 6.6\%) among those with bad obstetric outcomes though the values were not statistically significant. ${ }^{15}$ The consistent findings from geographically different places point out that rubella could have been a cause of adverse pregnancy out come like abortion.

Earlier follow up studies from different states of the country among pregnant women reported that during pregnancy period, (Kerala 3\%, Andhra Pradesh 6.7\%, Delhi 8.3\%) has acquired rubella infection as evidenced by IgM estimation. ${ }^{6,10,15}$ In our study only $>5 \%$ of women were susceptible to future rubella infection. In the state the mean age of marriage of women were 23 years. Our subjects consisted cohorts of women (Mean age 24.7 years) who passed their childhood before the introduction of any type of rubella vaccine in the country, hence were exposed to natural rubella infection. But in future due to sub population rubella vaccination as practiced now, the situation may change. The susceptibility may increase many folds among adult women due to waning of immunity and build up of non exposed cohorts leading to "age shifting".,2,12,13

Recently childhood rubella vaccination was introduced as combined form (Mumps, Measles, and Rubella) in few states of India at the age of 18 months as substitution for second dose of measles. The policy makers have to learn lessons from other countries which introduced rubella vaccination only among children. A tropical country Saudi Arabia has introduced rubella vaccine in childhood immunization programme in 1980s and later serological studies among adult women found that the immunity level among them were decreased significantly and progressively with increasing women's age. So they introduced adolescent and subsequent adult vaccination. ${ }^{17}$ In Greece the hap hazardous unplanned rubella vaccination programme among a little proportion of children during early 1970s resulted in Rubella out breaks in adults and CRS after two decades due to "paradoxical effect" was reported widely. ${ }^{1,12,13}$

Based on the data available from systematic review it was estimated that in India among new born serologically confirmed CRS will be 9 per one lakh new born, with 27 million birth cohorts it will be approximately 2430 in numbers (Estimated by the Author). ${ }^{8}$ In children 1.5\% blindness and $1.7 \%$ of deafness were due to CRS and, $4-5 \%$ congenital cardiac diseases were attributed due to CRS. ${ }^{8}$ Caring for CRS cases is costly because of the permanent disabilities.. India being a WHO member in South East Asian region, had declared CRS elimination as a goal. ${ }^{5}$ Although rubella vaccine is safe and effective, clear policy regarding rubella immunization of children either at 15 months or young girls at 9 to 12 Years have not been outlined in India. For controlling CRS, the 'indirect strategy' is to immunize children and reduce transmission of rubella, and the 'direct strategy' is to immunize adolescents, or adults to prevent rubella infection and CRS. ${ }^{12,13}$ The first may pose a risk to adults and the second cannot prevent rubella transmission as described, so both are be needed in a combined, coordinated form. By including rubella vaccination in childhood UIP with high coverage of above $85 \%$ CRS elimination will take more than 30 years. Along with children if the adolescents are included in vaccination programme it will take 10-20 years. When vaccine is given to children, adolescents and women 
of reproductive age group CRS will be eliminated immediately within 10 years which is cost effective. ${ }^{11,18}$ In the absence of immunization of adult population, rubella continues to circulate resulting in ongoing exposure of pregnant women and the associated risk of CRS .Countries planning to introduce rubella vaccine should review the epidemiology of rubella, assess the burden of CRS, and establish rubella/CRS prevention as a public health priority and should formulate vaccination strategies accordingly. ${ }^{1,5}$

\section{CONCLUSION}

Due to feasibility we could not replace the missed out, so the sample size was limited to 70 .This community based study from Kerala state indicates that like many other Asian countries rubella is an endemic condition in India. Majority of adult women have got acquired immunity towards rubella and there is a requirement of detailed study for identification and its influence on prenatal morbidity due to CRS. More detailed epidemiological studies by taking samples from different states may be needed for measuring the susceptibility to rubella among pregnant women and future risks for CRS.

\section{ACKNOWLEDGEMENT}

This study was funded by State Board of Medical Research (SBMR) Directorate of Medical education, Government of Kerala. India.

The authors express thanks to the Staff PHC- Medical College Health Unit, Cheruppa, Mavoor, and the pregnant women in the area who cooperated with the study.

Thanks to Dr Thomas Bina, Head of the Department Community Medicine for the help and Dr Rema Devi Former Head of the Department of Microbiology, for laboratory support for the study.

\section{CONFLICT OF INTEREST}

Nil.

\section{ABBREVIATION USED}

CRS: Congenital Rubella Syndrome; UIP: universal immunization program; ELIZA: enzyme linked immunesorbent assay; WHO: World Health Organization ; NABL: National Accreditation Board for Testing Laboratories; CI: confidence intervals; PHC: primary health centre; IgG: Immunoglobulin G.

\section{REFERENCES}

1. Rubella vaccines: WHO position paper. Wkly Epidemiol Rec. 2011:86:301-16 PMid:21766537.

2. Taneja DK Sharma P. Targeting rubella for elimination. Indian J Public Health. 2012;56(4):269-72. http://dx.doi.org/10.4103/0019-557X.106413; PMid:23354136.

3. Singla N, Jindal N, Aggarwal A. The seroepidemiology of rubella in Amritsar (Punjab). Indian Journal of Medical Microbiology. 2004;22(1):61-3. PMid:17642690

4. Cutts FT, Robertson SE, Diaz-Ortega JL, Samuel R. Control of rubella and congenital rubella syndrome (CRS) in developing countries, part 1: burden of disease from CRS. Department of Vaccines And Biologicals. Geneva: World Health Organization; 2000. p. 5. Gavin BG, Susan ER, Alya D, Gacic-Dobo M, Peter MS. Rubella and congenital rubella syndrome control and eliminationglobal progress, 2000-2014. WHO. Weekly Epidemiological Record. 2015;510-6.

5. Gupta E, Dar L, Broor S. Seroprevalence of rubella in pregnant women in Delhi, India Indian J Med Res. 2006;123:833-5. PMid:16885608.

6. Yadav S, Gupta S, Kumari S. Sero-prevalence of rubella in women of reproductive age group. Indian J Pathol Microbiol. 1995;38(2):139-42. PMid:8919097.

7. Pooja D, Piyush G. Burden of Congenital Rubella Syndrome (CRS) in India: A Systematic Review. Indian Pediatrics. 2012;49(5):377-99. http://dx.doi. org/10.1007/s13312-012-0087-4

8. Jubaida N1, Mondal MEA2, Kawsar NM3. Seroprevalence of Rubella Antibodies in Pregnant Women. JAFMC Bangladesh. 2011;7:20-4

9. Padmaja M, Radhakrishna PM, Sam JV. Seroprevalence of immunity to rubella in pregnant women. The National Medical Journal of India. 2010;23(4):248-9. PMid:21197723.

10. Ramana BV, Reddy BK, Murthy DS. Seroprevalence of Rubella in Women with Bad Obstetric history. J Family Med Prim Care. 2013:2(1):44-6. http://dx.doi. org/10.4103/2249-4863.109943 ; PMid:24479042 PMCid:PMC3894004.

11. Cutts FT, Metcalf CJE, Lessler J, Grenfell BT. Rubella vaccination: must not be business as usual. Lancet. 2012;380(9838):217-8. http://dx.doi.org/10.1016/ S0140-6736(12)61215-X.

12. Takis $P$, Ioanna A, ValassiAdam E. Increase in congenital rubella occurrence after immunization in Greece: retrospective survey and systematic review. BMJ. 1999;319(7223):1462-65. http://dx.doi.org/10.1136/bmj.319.7223.1462.

13. Ananya G, Parul J, Amita J. Sero-prevalence of Rubella Virus Antibodies in Pregnant Women in the Vicinity of Luck now, Uttar Pradesh. Archives of Medicine. 2015;7:3 Available from. www.archivesofmedicine.com. Last cited on March. 282016.

14. Ramana BV, Reddy BK, Murthy DS. Seroprevalence of Rubella in Women with Bad Obstetric history J Family Med Prim Care 2013:2(1):44-6. http://dx doi. org/10.4103/2249-4863.109943 ; PMid:24479042 PMCid:PMC3894004.

15. Jayakrishnan T, Kunyil V, Anitha PM, Rao B. Prevalence Of Rubella Specific IGg Antibodies In Un immunized Young Female Population (Un Published)

16. Sharifa AA. Rubella Immunity among Pregnant Women in Jeddah, Western Region of Saudi Arabia. Obstetrics and Gynecology International .2014: Article ID 659838, 6 pages. http://dx.doi.org/10.1155/2014/659838. Last cited on April 1st 2016. http://dx.doi.org/10.1155/2014/659838.

17. Robertson SE, Cutts FT, Samuel R, Diaz-Ortega JL. "Control of rubella and congenital rubella syndrome (CRS) in developing countries, part 2: vaccination against rubella," Bulletin of the World Health Organization. 1997;75(1):69-80. PMid:9141752 PMCid:PMC2486979. 